\title{
Quantifying the effectiveness of agri- environment schemes for a grassland butterfly using individual-based models
}

Article

Accepted Version

Creative Commons: Attribution-Noncommercial-No Derivative Works 4.0

Evans, L. C., Sibly, R. M., Thorbek, P., Sims, I., Oliver, T. H. and Walters, R. J. (2019) Quantifying the effectiveness of agrienvironment schemes for a grassland butterfly using individual-based models. Ecological Modelling, 411. p. 108798. ISSN 0304-3800 doi:

https://doi.org/10.1016/j.ecolmodel.2019.108798 Available at https://centaur.reading.ac.uk/85990/

It is advisable to refer to the publisher's version if you intend to cite from the work. See Guidance on citing.

To link to this article DOI: http://dx.doi.org/10.1016/j.ecolmodel.2019.108798

Publisher: Elsevier

All outputs in CentAUR are protected by Intellectual Property Rights law, including copyright law. Copyright and IPR is retained by the creators or other copyright holders. Terms and conditions for use of this material are defined in the End User Agreement. 


\section{CentAUR}

Central Archive at the University of Reading

Reading's research outputs online 
Quantifying the effectiveness of agri-environment schemes for a grassland butterfly using individual-based models

Authors: Luke C. Evans ${ }^{*}$, Richard M. Sibly ${ }^{1}$, Pernille Thorbek ${ }^{2,4}$, Ian Sims $^{2}$, Tom H. Oliver ${ }^{1}$ and Richard J. Walters ${ }^{1,3}$

*Corresponding author: 1.c.evans@pgr.reading.ac.uk

\section{Author affiliations:}

1. School of Biological Sciences, University of Reading, Whiteknights, PO Box 217, Reading, Berkshire, RG6 6AH, UK

2. Syngenta, Jealott's Hill International Research Centre, Bracknell, Berkshire RG42 6EY, UK

3. Centre for Environmental and Climate Research, University of Lund, Sweden

4. BASF SE, APD/EE, Speyerer Strasse 2, 67117 Limburgerhof, Germany

\section{Author contributions:}

LE collected the data, conducted the analysis and developed code for the individual-based model. LE, RS \& RW led the writing of the manuscript with contributions from TO, IS \& PT.

\section{Data accessibility statement:}

Should the manuscript be accepted, the data supporting the results and all model code, will be archived in a public repository such as Dryad or Figshare and the data DOI will be included at the end of the article.

Keywords: movement-ecology, energy-budgets, Lepidoptera, Maniola jurtina, conservationmanagement

Abstract: 254

Main text: 5854

References: 76

Figures: 4

Tables: 2

Supplementary: 3 


\section{Abstract}

The intensification of agricultural practices throughout the twentieth century has had large detrimental effects on biodiversity and these are likely to increase as the human population rises, with consequent pressure on land. To offset these negative impacts, agri-environment schemes have been widely implemented, offering financial incentives for land-owners to create or maintain favourable habitats that enhance or maintain biodiversity. While some evidence is available on the resulting species richness and abundance for groups such as natural predators and pollinating insects including butterflies and moths. This is costly to obtain and it is difficult to predict the effects of specific habitat designs. To alleviate this problem we here develop an individual-based model (IBM), modelling the detailed movement behaviour, foraging, and energy budget of a grassland butterfly Maniola jurtina Linn. in patches of varying dimensions and quality. The IBM is successfully validated against data on M. jurtina densities, movement behaviour, resource use, fecundity and lifespan in habitats of varying quality. We use the IBM to quantify the benefits for life-history outcomes of $M$. jurtina of increasing the quantity and the quality of field margins within agricultural landscapes. We find that increasing the quantity of field margin habitat from 1 to 3 ha per 100 ha, as recommended in agri-environment schemes, increases the average number of eggs laid across a two-week period by $60 \%$ and adds an extra day to the average lifespan of the butterfly. Similar effects are reported for variation in the quality of field margins. We discuss the implications of the result for modelling butterfly responses to management scenarios. 


\subsection{Introduction}

Agricultural practices have intensified throughout the twentieth century to keep pace with needs of growing populations (Duraiappah et al., 2005), a trend that is set to continue well into the twenty-first century (Lutz et al., 2017), and that is the main driver of insect declines occurring at a global scale (Sánchez-Bayo and Wyckhuys, 2019). In the UK, agricultural landscapes have tended toward increasing simplification with less variety in crop rotations implemented at the farm scale (Robinson and Sutherland, 2002) and increases in the size of land parcels used for intensive agriculture (Petit et al., 2002). Intensification has had detrimental effects on biodiversity (Robinson and Sutherland, 2002) notably on farmland birds (Chamberlain et al., 2000; Donald et al., 2006), pollinating insects (Potts et al., 2016; Vanbergen et al., 2013), wildflowers (Barr et al., 1994), and butterflies (Asher et al., 2001; Ekroos et al., 2010; Fox et al., 2015; Pywell et al., 2004).

For pollinating insects, a mechanism associated with their declines is reduction in the availability of floral resources (Biesmeijer et al., 2006; Goulson et al., 2015; Potts et al., 2010), which in the UK, have occurred at the national scale (Baude et al., 2016). A major tool to offset these effects is agri-environment schemes, a key aspect of which is to offer landowners various financial incentives to implement management increasing the quality or amount of habitat for wildlife within agricultural landscapes. A widely advocated approach, both within the UK and Europe, for increasing resources available to insects within intensive landscapes, is the use of enhanced field margins (Vickery et al., 2009). Payments for flowerrich margins and plots are currently delivered in England through the Countryside Stewardship Scheme (CSS) (Defra, 2019). The continuing development of guidelines for these schemes requires measuring and predicting the responses of species to management. This is a challenging task, though research is beginning to accumulate concerning the necessary quantity of quality habitat required to support groups such as pollinators (Dicks et al., 2015; Redhead et al., 2015; Sutton et al., 2017). This information subsequently informs guidelines, such as the CSS guidance of 1-3\% of land set aside for nectar-rich plots and field margins.

Butterflies are useful indicators of environmental quality (Erhardt and Thomas, 1989) as populations respond rapidly to environmental change (Thomas, 2005), thus they represent useful model organisms for understanding the wider benefits of agri-environment schemes 
for terrestrial insects. Butterflies gain multiple benefits from field margins (Dover, 2019), and florally enhanced margins provide nectar resources for the adults which have important consequences for individual fecundity, longevity, dispersal (Geister et al., 2008; Lebeau et al., 2016a, 2016b; Watt et al., 1974), and species richness and abundance (Curtis et al., 2015; Luppi et al., 2018). Therefore, predicting the responses of butterflies to agri-environment schemes has direct application in conservation management. Butterflies are a well-studied group and empirical data exist for the development and validation of models that could predict the responses of butterflies to agri-environment schemes, providing insight into the responses of species to a multitude of scenarios that would otherwise be expensive in time and cost to study in the field.

Modelling the movement behaviour of adult butterflies has received much attention. Examples included responses to boundaries (Delattre et al., 2013; McIntire et al., 2013; Ovaskainen and Hanski, 2004; Schultz et al., 2012; Schultz and Crone, 2001) and habitatdependent changes in butterfly movement rates (Fownes and Roland, 2002; Odendaal et al., 1989; Ovaskainen et al., 2008b; Roland et al., 2000; Schtickzelle et al., 2007; Zalucki and Kitching, 1982). More recently, individual-based models (IBMs), which allow for greater complexity in model processes, have been used to explore intraspecific variation in dispersal (Brown and Crone, 2016a), minimum area requirements (Brown and Crone, 2016b), the effects of weather (Chapter 4) and perceptual range and spatial memory on butterfly movement (Grant et al., 2018). IBMs are suited to modelling the responses of butterflies to agri-environment schemes as they allow detailed interactions of individuals to their local environment and particularly responses to food availability through physiological energy budgets (Sibly et al., 2013). Further, butterfly movement responds to the composition and structure of the environment (Shreeve, 1995) and so in intensive landscapes, which contain small amounts of quality habitat, it is necessary to represent fine-scale behavioural changes.

Here we present a new IBM of adult butterfly behaviour that predicts life-history outcomes (primarily fecundity and survivorship) for females of a grassland butterfly, the Meadow Brown (M. jurtina), in response to changing structures and resource densities within a landscape. M. jurtina is a model butterfly species because aspects of its behaviour, physiology and life history are well described, making it an ideal system for parameterising an IBM. The IBM includes components representing the movement, energy budget, foraging behaviour and egg maturation throughout a butterflies' lifespan. The IBM is validated against four datasets, providing independent patterns for validation purposes (Grimm, 2005). After 
validation, the model is used to evaluate the effects on butterfly vital rates of varying proportions and qualities of flower-rich set-aside within agricultural landscapes. We discuss these findings in relation to the movement ecology of butterflies and the ways in which IBMs can be used for ecological forecasting and conservation management.

\section{Methodology}

\subsection{Study species and behavioural observations}

We provide a brief overview of data collection as the full details of most field observations have been presented in Chapters 2 and 3. Additional new data collected for this project were transects, that are described below, and edge responses, which are presented in Appendix D.

The meadow brown ( $M$. jurtina) is a common butterfly found across a variety of grasslands in the British Isles (Brakefield, 1982a). The adults obtain nectar from a range of flowers common to grasslands (Dennis, 1992) and the larvae feed predominantly on Poa spp. and occasionally on other grasses and common herbs. Flight paths of $235 \mathrm{M}$. jurtina females were recorded at four sites in the south of England over the summers of 2016, 2017 and 2018, North farm in Oxfordshire $\left(51^{\circ} 37^{\prime} \mathrm{N}, 1^{\circ} 09^{\prime} \mathrm{W}\right)$, Jealott's Hill farm Berkshire $132\left(51^{\circ} 27^{\prime} \mathrm{N}\right.$, $\left.0^{\circ} 44^{\prime} \mathrm{W}\right)$, the University of Reading $\left(51.4414^{\circ} \mathrm{N}, 0.9418^{\circ} \mathrm{W}\right)$, and Sonning farm Berkshire $\left(51^{\circ} 28^{\prime} \mathrm{N}, 0^{\circ} 53^{\prime} \mathrm{W}\right)$. Positions of butterflies were mapped every time the butterfly landed or after 15 seconds of continuous flight using numbered flags. The precise coordinates were subsequently mapped using a high-grade Global Navigation Satellite System receiver accurate to $<30 \mathrm{~cm}$ (Arrow 200 RTK). Simultaneously the behaviour of the butterflies was recorded (basking, inactive, flying, nectaring, and oviposition). Observations either ceased after 10 minutes or after a set number of flags were laid (20 in 2016 \& 2017, 15 in 2018).

Butterfly transects were walked along field margins and at two paired 'ghost' margins parallel to the field margin and spaced at approximately 5 and $10 \mathrm{~m}$ into the crop field (measurements were approximate as transects were walked in the nearest furrow to avoid crop damage). Butterfly counts were recorded using standard methods (Pollard and Yates, 1994). Briefly, this consisted of observers starting in a margin and then recording the number of individuals of $M$. jurtina within a $5 \mathrm{~m}$ box of the observer while walking at a set pace for 200 metres. The observer then moved to the next transect and repeated the procedure. This generated three paired transects showing butterfly counts within the field margin and then 5 
and 10m into the crop. In total 356 transects were walked between 10:00 and 17:00 at eight field margin locations during August 2016 and June-August 2017 (Appendix D2).

\subsection{Model overview}

The model is a spatially-explicit simulation of the movement, foraging and egg-laying of adult individual female $M$. jurtina. The model runs at one-second time-steps replicating the behaviour of the butterflies over their lifespan. Physiological processes within each individual are modelled, together with a detailed representation of its movement behaviour. The energy use of butterflies during flight and inactivity is represented over the full 24 hour period each day, with rates parameterised from observed values (Table. 1). Butterflies in the simulation perceive flowers and extract energy at values parameterised from empirical observations of nectar sugars in flowers, and females mature and lay eggs throughout the simulation. This allows prediction of how the quantity and quality of the flower-rich patches in the landscape affect the fecundity, lipid reserves and survivorship of M.jurtina; outcomes which are informative metrics for conservation management. The movement behaviour includes recent advances in butterfly IBMs such as the explicit representation of flight and inter-flight durations (Brown and Crone, 2016a), responses to habitat edges (Conradt et al., 2000; Conradt and Roper, 2006) and foraging loops which spontaneously occur in our model as butterflies perceive and preferentially move to higher quality habitat (Grant et al., 2018).

The model was built in NetLogo 6.0 (Wilensky, 1999) and analysis was carried out using the RNetLogo package (Thiele, 2014). Von-Mises circular distributions were fitted to observed turning angles using the 'circular' package in R 3.4.2 (Lund and Agostinelli, 2011; R Core Team, 2017).

The model is described using the Overview, Design concepts and Details format (ODD protocol) (Grimm et al., 2010, 2006). A more comprehensive technical specification is presented in Appendix D. 


\subsection{Generic model description}

\subsubsection{Entities, state variables and scales}

The model landscape consists of two-dimensional $5 \mathrm{~m}^{2}$ patches that are either flower-poor or flower-rich. Flower-rich patches contain entities called 'flowers' while flower-poor patches do not. Butterflies forage and lay eggs in flower-rich patches, which in the experimental simulations represent field margins. Butterflies are described by their age, sex, spatial location, energy reserves (mobilised and lipid energy reserves), movement rate, flight and resting metabolic rates, the number of immature oocytes, mature eggs and the total number of eggs successfully laid. Flowers provide replenishing supplies of nectar sugar and are described by their location, energy content and the replenishment time of their nectar resources. The model proceeds in one-second time-steps. For evaluating the response of butterflies to field margin design over a two-week period, the spatial extent of the landscape was $100 \mathrm{ha}(1000 \times 1000 \mathrm{~m})$ and the flower-rich patches were arranged in lines to represent field margins (Fig. 1, 2.7 Exploration of the effects on butterflies of field margin design).

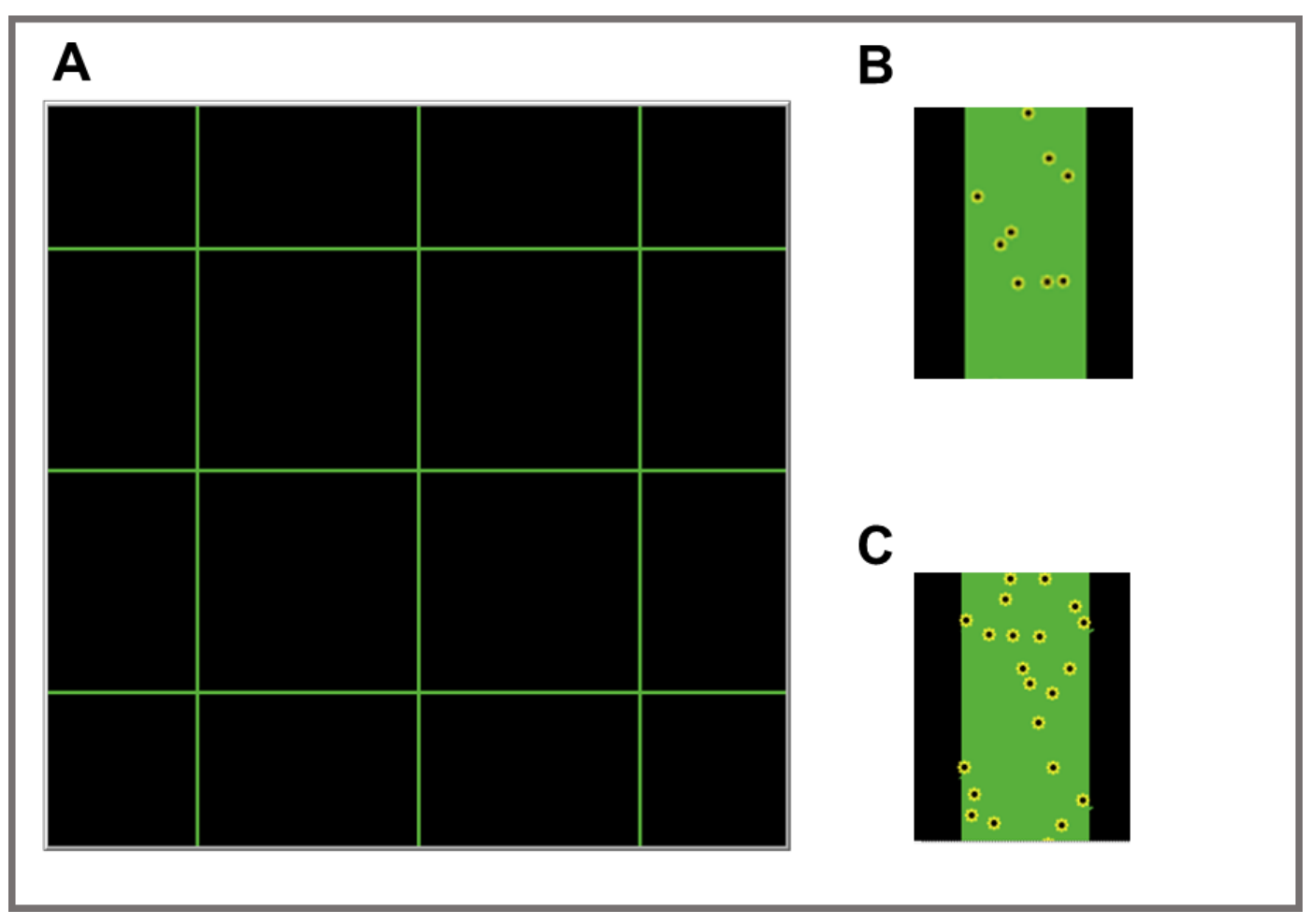

Figure 1. Simulated landscapes. A) Field margins, flower-rich patches are green, flower-poor patches are black; examples of flower-rich patches B) with low density of flowers, C) with increased density of flowers. Flowers are shown in yellow. 


\subsubsection{Model schedule}

Here we present an overview of the model (Fig. 2); further details of the model processes are available in the section sub-models below and in Appendix D. Butterflies are conceptualised as having two sources of energy: lipid stores and mobilised energy collected during foraging. Mobilised energy is used preferentially and lipid reserves are only used when no mobilised energy is available. At each time step, butterflies with no remaining lipid stores are considered to have died and are removed from the simulation. During the day, butterflies move and forage, with movement rates dependent on the type of patch. Slower tortuous flights occur in flower-rich patches and straighter faster flights in the flower-poor patch. Flight and inter-flight periods are represented explicitly, with the butterflies drawing alternatively from the observed distributions of these behaviours. During inter-flight periods, the butterflies remain stationary and use energy at the resting metabolic rate (RMR), while during flight energy use is at the flight metabolic rate (FMR). During a flight, movement is represented as a modified correlated random walk - individuals draw step distances from habitat-specific distributions of step lengths observed for flights of that duration. For example, if a four-second flight was drawn, a step from the distribution of step lengths observed after four-second flights would be selected. The butterfly then moves forward at a rate such that the step length is completed in the flight time (speed = step distance / step duration). As step lengths were measured up to a maximum of every 15 seconds a long flight may result in multiple steps being drawn before the flight has been completed. At the end of each step and flight, a new heading is drawn from a habitat-specific distribution and added to the current heading. If butterflies encounter the edge of a flower-rich patch a probabilistic decision is made to either redirect their flight path to remain within the habitat or to cross into the flower-poor patch. Butterflies within the flower-poor patches can perceive flower-rich patches at a distance of $50 \mathrm{~m}$ and a probabilistic decision is made to either direct flight towards the nearest flower-rich patch or to maintain the direction of their current flight path. Butterflies with no mobilised energy that are in flower-rich patches, search for flowers, with a flower considered discovered if a butterfly lands within a metre at the end of a flight - for simplification, this ignores the small movements that take place as butterflies land on flowers. The butterfly then extracts nectar to gain energy that is added to the mobilised store; lipid stores are never replenished. As M. jurtina is protandrous and monandrous (Brakefield, 1982b; Scali, 1971), and typically quickly mated after emergence, we assume all females are fertile from initiation. Eggs are then matured at a set rate and when ten mature eggs are available, butterflies lay eggs in flower-rich patches. At the end of each day (ten hours of 
simulated time) a 14 hour night period commences during which temperature corrected RMR and egg maturation take place.

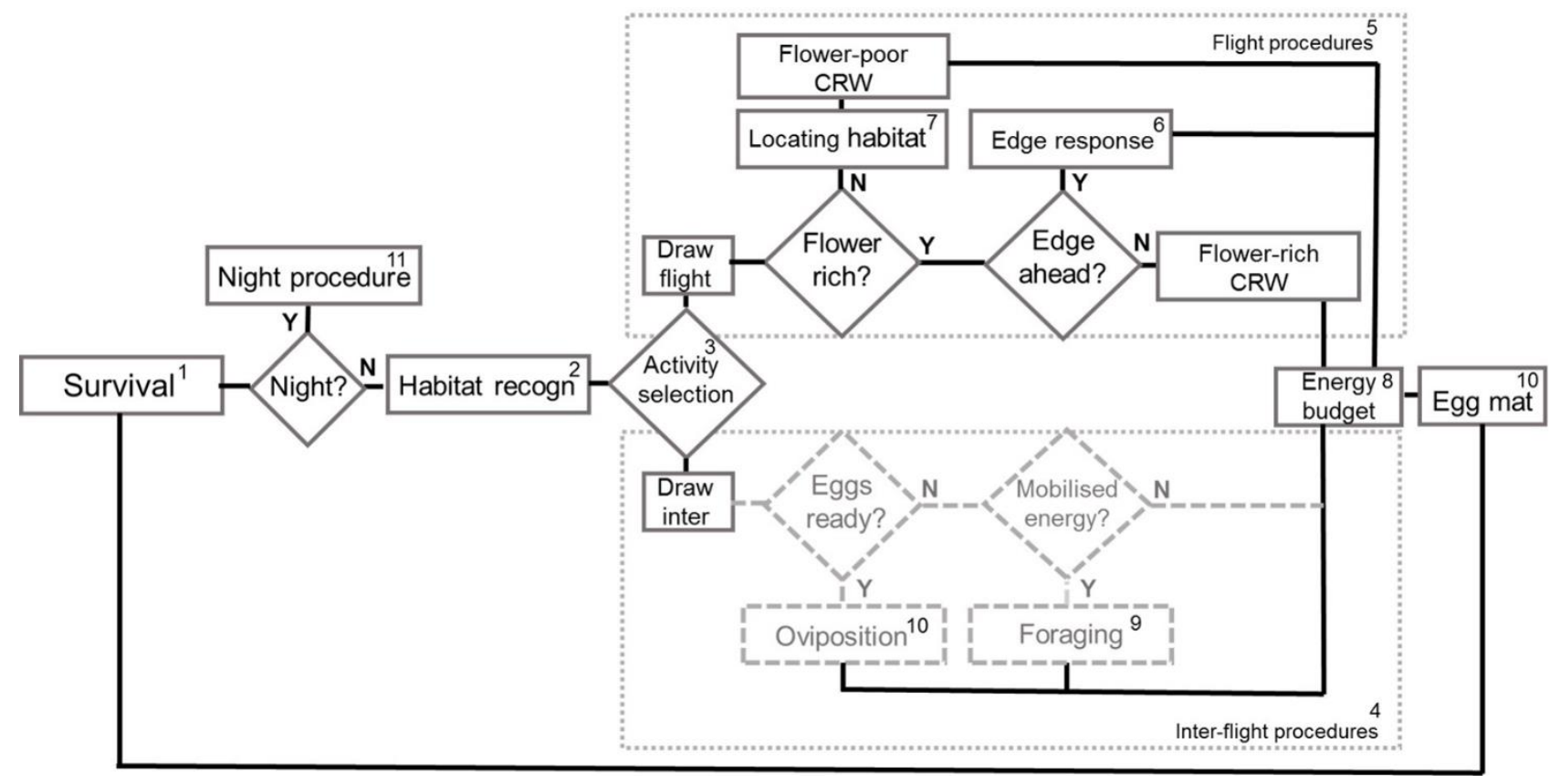

Figure 2. Conceptual model. Dark grey boxes run every time-step while light grey dashed boxes take place only the first time the inter-flight procedures are called. CRW refers to correlated random walk. Numbers 1-11 refer to model processes detailed below in 2.3.3 Submodels.

\subsubsection{Submodels}

Here we present an overview of the submodels. Full details of the submodel processes, including equations and supporting literature, are available in Appendix A. Where data below are drawn from field observations these are presented in Chapter 5.

1. Survival. Butterflies with no lipid or mobilised energy stores are considered to have died and are removed from the simulation.

2. Habitat recognition. Butterflies determine whether their current location is in a flower-poor or flower-rich patch. This subsequently affects processes in flight and interflight. 
3. Activity selection. Butterflies select their next activity, which cycles between periods of flight or inter-flight. The duration of flights and inter-flights is drawn from distributions of those observed in the field and is habitat-specific.

4. Inter-flight. Between flights, butterflies remain stationary. RMR takes place.

5. Flight. Butterflies move across the landscape according to a correlated random walk until the current flight time has elapsed. The rate of movement and the straightness of flight is habitat-specific and is drawn from distributions collected from field observations. FMR and egg maturation take place.

6. Edge response. Butterflies in flight detect the edges of flower-rich patches and can redirect their movement to remain in the flower-rich patch or cross into a flower-poor patch at a set probability.

7. Locating new habitat. Butterflies in flower-poor patches can redirect their flight towards flower-rich patches that can be perceived visually at a distance of 50 metres. The choice to direct flight towards flower-rich patches is undertaken at a set probability. Butterflies that select to return to a flower-rich patch fly directly towards the nearest such patch.

8. Energy budget. The energy loss of butterflies is determined by whether the butterfly is in inter-flight (RMR) or flight (FMR). Available energy is either mobilised energy in the form of sugars derived from foraging, or in the individual's non-replenishing lipid stores. Energy is subtracted first from the mobilised energy until it is exhausted at which point the butterfly draws on its lipid stores.

9. Foraging. Butterflies with no mobilised energy forage for flowers. Butterflies in flower-rich patches that land within a metre of a flower extract nectar to gain mobilised energy. The time taken to extract nectar is taken from field observations of nectaring durations and is added to the inter-flight time. After nectar has been extracted from flowers they cannot supply further nectar until one hour of simulation time has elapsed, thereafter nectar is again available. The amount of energy per flower is estimated from field observations of nectar production and content (Hicks et al., 2016).

10. Egg maturation \& oviposition. Female butterflies initially have a supply of 200 immature oocytes that mature into eggs during the simulation. Egg maturation requires the provision of lipid from the lipid energy stores at a rate observed in laboratory experiments 
(Berger et al., 2008). When ten eggs have been matured, eggs can be laid in flower-rich patches. Specific details of the egg-laying behaviour of the butterfly are not modelled explicitly within the simulation and only the total number of eggs laid is recorded.

11. Night. Every ten hours of simulated time a night procedure is called during which body temperature is assumed to be ambient air temperature and energy is lost through temperature-corrected RMR and egg maturation rates using Arrhenius kinetics.

\subsubsection{Initialisation}

Population size varies between simulation experiments (see below) and is set on initialisation.

Butterflies are located randomly. Flowers are located randomly within flower-rich patches.

Default parameters used during the simulation are shown below in Table 1. 
Table 1. Default parameter values of the butterfly model with sources. Further details of parameter estimates are available in Appendix D.

\begin{tabular}{|c|c|c|c|c|}
\hline Parameter & Value & Units & Reference & Notes \\
\hline Flight durations ${ }^{\dagger}$ & $13 *$ & $s$ & -- & \\
\hline Inactive durations ${ }^{\dagger}$ & $64 *$ & $s$ & -- & \\
\hline Nectar durations & $57 *$ & $s$ & -- & \\
\hline $\begin{array}{l}\text { Resting metabolic } \\
\text { rate }\end{array}$ & $0.13 *$ & $m l \mathrm{CO}_{2}$ hour $^{-1}$ & $\begin{array}{c}\text { (Lebeau et al., } \\
\text { 2016a) }\end{array}$ & \\
\hline $\begin{array}{c}\text { Flight metabolic } \\
\text { rates }\end{array}$ & $0.82 *$ & $m l \mathrm{CO}_{2}$ hour $^{-1}$ & $\begin{array}{c}\text { (Lebeau et al., } \\
\text { 2016a) }\end{array}$ & \\
\hline Mass & $100 *$ & $m g$ & $\begin{array}{c}\text { (Lebeau et al., } \\
\text { 2016a) }\end{array}$ & \\
\hline Step distances $\dagger$ & $4.6^{*}$ & $m$ & -- & \\
\hline Edge crossingt & 0.39 & -- & -- & Calibrated \\
\hline Habitat returning & 0.004 & -- & -- & Calibrated \\
\hline $\begin{array}{c}\text { Assimilation } \\
\text { efficiency }\end{array}$ & 0.98 & $\%$ & $\begin{array}{c}\text { (Hainsworth et } \\
\text { al., 1991) }\end{array}$ & Vanessa cardui \\
\hline Energy of sugar & 16.74 & $J m g^{-1}$ & $\begin{array}{c}\text { (Clements, } \\
\text { 1992) }\end{array}$ & \\
\hline Energy of lipid & 40 & $J m g^{-1}$ & (Kleiber, 1961) & Dry mass \\
\hline $\begin{array}{c}\text { Joules per ml of } \\
\mathrm{CO}_{2}\end{array}$ & 21.1 & $J m l^{-1}$ & $\begin{array}{l}\text { (Hill et al., } \\
\text { 2004) }\end{array}$ & \\
\hline $\begin{array}{l}\text { Lipid fraction of } \\
\text { body }\end{array}$ & $\begin{array}{c}20 \text { (on } \\
\text { emergence) }\end{array}$ & $\%$ & $\begin{array}{c}\text { (Vande Velde } \\
\text { and Van Dyck, } \\
\text { 2013) }\end{array}$ & Parage aegeria \\
\hline $\begin{array}{c}\text { Flower } \\
\text { replenishment }\end{array}$ & 1 & hour & $\begin{array}{l}\text { (Luo et al., } \\
\text { 2014) }\end{array}$ & \\
\hline $\begin{array}{c}\text { Sugar per flower } \\
\text { unit }\end{array}$ & $\begin{array}{l}0.061 * \\
0.002 *\end{array}$ & $m g$ hour $^{-1}$ & $\begin{array}{c}\text { (Hicks et al., } \\
\text { 2016) }\end{array}$ & C. nigra, T.pratense \\
\hline $\begin{array}{l}\text { Egg maturation } \\
\text { rate }\end{array}$ & 0.564 & Eggs hour ${ }^{-1}$ & $\begin{array}{c}\text { (Berger et al., } \\
\text { 2008) }\end{array}$ & $\begin{array}{l}P . \text { aegeria at } 30^{\circ} \mathrm{C} \\
\text { rate depends on } \\
\text { temperature and age }\end{array}$ \\
\hline Activation energy & 0.62 & $e V$ & & \\
\hline $\begin{array}{c}\text { Reference } \\
\text { temperature }\end{array}$ & 30 & ${ }^{o} \mathrm{C}$ & $\begin{array}{c}\text { (Lebeau et al., } \\
\text { 2016a) }\end{array}$ & $\begin{array}{l}\text { Day time metabolism } \\
\text { and egg maturation }\end{array}$ \\
\hline $\begin{array}{c}\text { Energy of lipid per } \\
\text { egg }\end{array}$ & 0.4 & $\mathrm{~J}$ & $\begin{array}{l}\text { (Wiklund and } \\
\text { Karlsson, } \\
\text { 2019) }\end{array}$ & \\
\hline $\begin{array}{c}\text { Lipid fraction of } \\
\text { egg }\end{array}$ & 7 & $\%$ & $\begin{array}{l}\text { (García-Barros, } \\
\text { 2006) }\end{array}$ & Wet mass \\
\hline $\begin{array}{c}\text { Maximum number } \\
\text { of immature } \\
\text { oocytes }\end{array}$ & 200 & & $\begin{array}{c}\text { (Brakefield, } \\
\text { 1982b; Grill et } \\
\text { al., 2013; } \\
\text { Lebeau, 2015) }\end{array}$ & $\begin{array}{c}\text { Maximum egg-laying } \\
\text { capacity in laboratory } \\
150-350\end{array}$ \\
\hline $\begin{array}{l}\text { Water fraction of } \\
\text { adult mass }\end{array}$ & 73 & $\%$ & $\begin{array}{c}\text { (Mazer and } \\
\text { Appel, 2001; } \\
\text { Scriber et al., } \\
\text { 2012; Wagner } \\
\text { and del Rio, } \\
\text { 1997) }\end{array}$ & $\begin{array}{c}\text { 63-73 reported across } \\
\text { species, P.aegeria } \\
\sim 73 \%\end{array}$ \\
\hline Sensory radius & 1,50 & $m$ & - & $\begin{array}{c}\text { Flowers, flower-rich } \\
\text { patches }\end{array}$ \\
\hline
\end{tabular}

* represents mean values from empirical distributions, $\dagger$ denotes parameters which are habitat-specific. 


\subsubsection{Emergence}

Four main features emerge from the model structure. First, the quantity of habitat within the landscape affects the reserves and subsequent longevity of the butterflies. Energy is used during inter-flight and flight, thus maintenance of lipid energy stores is supported by access to nectar provided by flowers and collected during foraging. Second, landscape composition influences the total number of eggs laid by females, as lipid energy stores must be shared between metabolism for survival and egg maturation. Third, edge responses and locating new habitat cause changes in the density of butterflies in the field margin (flower-rich) and flower-poor patches. These behaviours increase the proportion of time spent in flower-rich patches that is likely adaptive behaviour for increasing foraging success and reproductive fitness. Further, the locating new habitat procedure generates an observed behaviour termed a foraging loop (Conradt et al., 2000; Conradt and Roper, 2006) which occurs when butterflies leave flower-rich patches but soon after return. Fourth, movement rates and activity are habitat-specific, this causes variability in displacement rates and population densities that are dependent on landscape composition.

\subsubsection{Adaptation}

Movement rates and activity change in response to habitat type that increases time spent in flower-rich habitat and reduces time in flower-poor habitat. Edge responses and locating new habitat are presumed to have similar effects. Butterflies are assumed to only take nectar when their mobilised resources are depleted, to leave time for fitness-enhancing behaviours which are not here explicitly modelled (i.e., mate detection, host plant detection, predator avoidance, basking and thermoregulation).

\subsection{Model calibration}

Probabilistic decisions in edge response and locating new habitat were calibrated using rejection Approximate Bayesian Computation (van der Vaart et al., 2015) to match model outputs to observed densities within field and ghost margins. Upper and lower values of a uniform prior for edge response were estimated from a small experiment conducted during data collection (Appendix D) and values reported in the literature (Conradt and Roper, 2006). Limits of a uniform distributed prior for locating new habitat were guestimated by relating observations of the proportion of butterflies performing foraging loops in the literature (Conradt and Roper, 2006) to those that would result from the model structure implemented. 
200 values were drawn from the priors using Latin hypercube sampling prior to the simulation (Thiele et al., 2014).

\subsection{Model validation}

The model was validated against five patterns observed for $M$. jurtina: an outdoor experiment measuring lipid used under varying resource availability (Lebeau et al., 2016b), field observations of egg-laying rates and survivorship (Brakefield, 1982b), butterfly densities within field margins, and medium-term displacement predictions for flower-poor and flowerrich patches.

Lebeau et al.'s experiment (Lebeau et al., 2016b) explored the relationship between metabolism, resource density, and lipid reserves. Twenty wild-caught individuals of $M$. jurtina were placed in an outdoor flight cage in either a high or low nectar treatment, which corresponded to 100 or 10 inflorescences per cage respectively. The resource densities were chosen to mimic field densities of resources observed in high and low-quality habitats. Flowers of the brown knapweed Centaurea jacea (Linn,) were used for the high nectar group and the red clover Trifolium pratense (Linn.), for the low nectar group. Butterflies were left for 48 hours and afterwards, individuals were collected and the remaining lipid reserves measured. The IBM was set up to replicate the experimental design. Twenty individuals were initialised in a 'flight cage' $(5 \times 10 \mathrm{~m}$ in the simulation) with access to either 100 or 10 flowers of the common knapweed Centaurea nigra (Linn.) or T. pratense. C. nigra was chosen to replace $C$. jacea as it is a closely related species with values of nectar sugar production available in the literature (Hicks et al., 2016). Butterflies were initialised with $16 \%$ dry body mass as lipid as it was assumed that wild-caught individuals would have lower lipid levels than those of freshly emerged individuals. As the focus was on changes in lipid reserves between treatments and not variation between individual butterflies, the butterflies were initialised with the same mass, FMR, and RMR across experiments by Lebeau et al., (2016b). Flight activity and movement during the simulation were derived from Chapter 5. The simulation was run for 48 hours of simulated time after which remaining reserves were converted to changes in the proportion of body mass as lipid. During the experiment, it was observed that flight activity of the low nectar group was reduced by $\sim 50 \%$ which had a small influence on predicted lipid use. To account for this we present results of simulations where this effect was approximated by halving the flight time (half-day of flight activity per day) in 
the low nectar group. The experiment was repeated ten times, simulating the response of 200 butterflies.

Fecundity and survivorship of natural populations of M.jurtina were measured in capturerecapture studies by Brakefield (Brakefield, 1982b). To compare these to model outputs, flower species and densities in the previous experiment were selected as representative of good and poor quality resource areas to which an intermediate category of resource density was added. A total of twenty butterflies were initialised in a flight cage and engaged in flight activity and movement for 30 days of simulated time or till there were no surviving butterflies. As butterflies differ in their initial mass, FMR and RMR which can influence longevity, the butterflies were initialised with individual masses, FMRs and RMRs at values by Lebeau et al., (2016b). The simulations were run for each resource density (10, 50, 100 per cage) and resource type ( $C$. nigra, $T$. pratense) combination providing six estimates of survival time and total eggs laid. Five repeats were conducted per treatment.

Ten-minute Euclidean displacements for M. jurtina across flower-rich and flower-poor habitats were reported in Chapter 5 and these were compared directly with model outputs of predicted displacement.

\subsection{Sensitivity analysis}

A local sensitivity analysis was performed to evaluate the influence of key parameters on lipid stores, which directly influence longevity and egg production. Each parameter in turn was adjusted $\pm 10 \%$, with 10 replicates, while other parameters held constant. Effects on lipid stores were recorded after 48 hours of simulated time.

\subsection{Exploration of the effects on butterflies of field margin design}

Two simulation experiments were conducted to explore the influence of quantity and quality of field margins within agricultural landscapes on the lipid use, longevity and fecundity of $M$. jurtina. In the first, the amount of land set-aside for field margins was varied with the density of nectar resources held constant. In the second experiment, the area of field margins was kept constant but the density of nectar resources within the field margins was varied.

For the first experiment, a 100 ha landscape was used and the area assigned to field margins was varied, being one of $0.5,1.0,1.5,2.0,2.5,3.0,3.5$ and 4 ha. These values cover the range 
of set-aside recommended for nectar-rich plots and margins in current agri-environment schemes (Defra, 2019). At the start of each simulation, each field margin patch was seeded with 25 flowers of C.nigra giving an intermediate flower density (Lebeau et al., 2016b) of 1 flower per $\mathrm{m}^{2}$. Butterflies were then randomly placed and the model was run for two weeks of simulated time after which longevity, total eggs laid per individual and the proportion of survivors were recorded. To observe any effects of population density the simulations were repeated with four initial population sizes $(500,5000,10000$ and 50000) for 10, 5, 2, and 1 replicates respectively.

For the second experiment, the same method was used but the number of C.nigra flowers per field margin patch was varied $(2,5,10,15,20,30,40$ and 50). The field margin area was held constant at $2.5 \mathrm{ha}$, the recommended value for flower-rich plots and margins per 100ha area in the current CSS guidance (Defra, 2019).

\section{Results}

\subsection{Validation}

IBM outputs matched all five data patterns well (Fig. 3 and below). The Euclidean distance moved in 10 minutes, here termed displacement, matched in both flower-poor and flower-rich habitats, though was slightly under-predicted in the flower-poor areas (Fig. 3A). Predicted and observed butterfly densities were very similar, though slightly under-predicted at 5 metres from the margin (Fig. 3B). Lipid content in the high and low nectar treatments of Lebeau et al., (2016a) was well predicted by the model (Fig. 3C). 

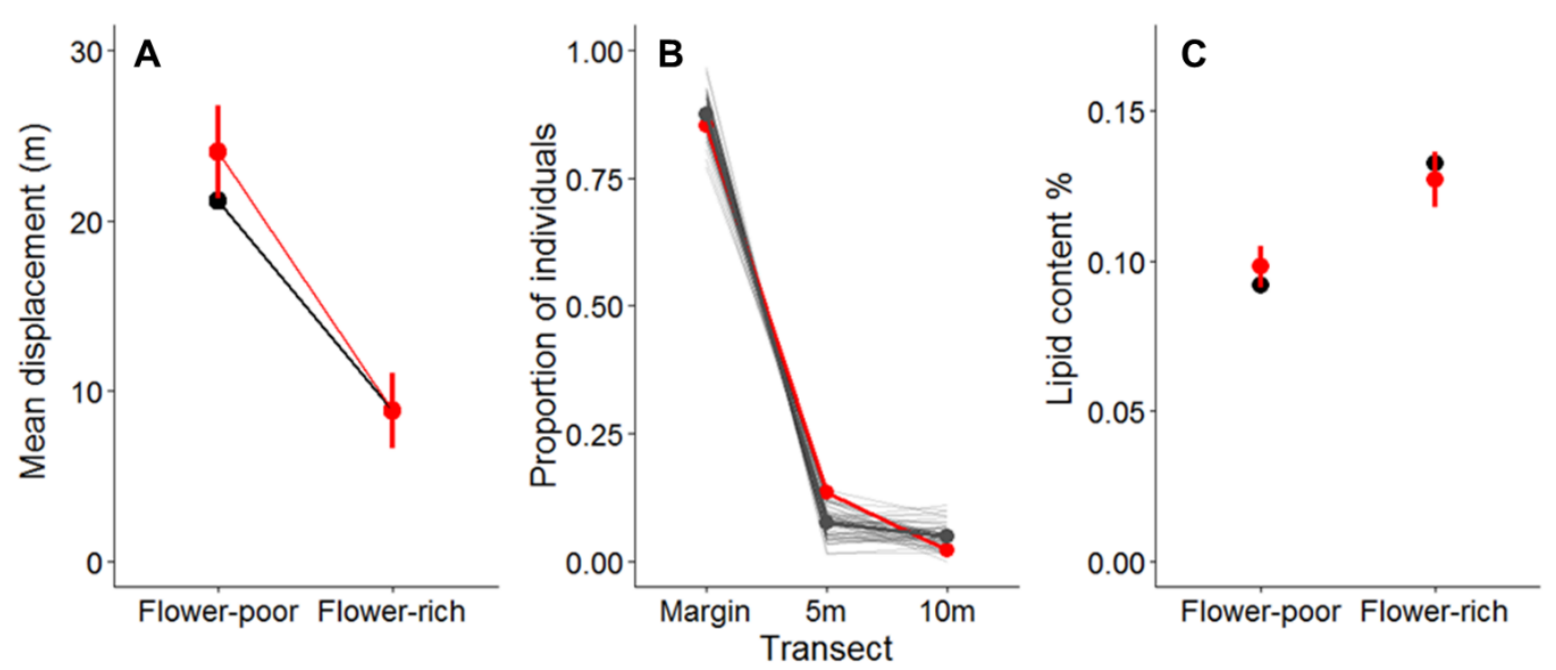

Figure 3. Match of model outputs to three data patterns. Data are presented in red and model predictions are in black. A) 10-minute displacements; B) densities of butterflies in field and ghost margins, individual model runs indicated by light grey lines; C) Change in lipid content over 48 hours between nectar poor and rich treatments, The data are obtained from Lebeau et al., (2016a).

Model outputs were also matched to data on fecundities and survivorship presented by Brakefield (1982b). In the absence of data on flower quality in Brakefield (1982b), flowers were simulated across a quality range bounded by the nectar poor and rich treatments of Lebeau et al., (2016a): the numbers of eggs produced by the butterflies (50 - 90) compared well with those reported $(66-80)$. Lifespans were also similar (predicted: 5.1 - 13 days, observed: 5-12 days).

\subsection{Sensitivity analysis}

The sensitivity of lipid use to key model parameters is shown in Table 2. Model outputs were the most sensitive to changes in flight and resting metabolic rates, and nectar sugar per flower. This is expected as these parameters have the most direct effect on an individual's energy balance. The next highest sensitivities were parameters involved with flight activity (inter-flight and flight durations) and the rate of nectar replenishment in flowers. Finally, the model was robust to variation in the radius of vision of butterflies for interacting with flowers and the rate of egg maturation. 
Table 2. The sensitivity of lipid use to changes in key parameter values presented as the average $\%$ change in output relative to $10 \%$ changes in parameter, \pm standard deviations. Signs demonstrate directions of change.

\begin{tabular}{cc}
\hline Parameter & $\begin{array}{c}\text { Relative sensitivity of lipid } \\
\text { use } \%\end{array}$ \\
\hline Inter-flight durations & $2.1 \pm 0.5$ \\
Flight durations & $-2.6 \pm 0.4$ \\
Resting metabolic rate & $-4.1 \pm 1.2$ \\
Flight metabolic rate & $-3.7 \pm 0.7$ \\
Vision radius & $0.3 \pm 1.0$ \\
Egg maturation rate & $-0.5 \pm 1.4$ \\
Nectar sugar content & $3.1 \pm 1.0$ \\
Nectar replenishment time & $-2.2 \pm 1.5$ \\
\hline
\end{tabular}

\subsection{Effects on butterflies of the design of field margins}

The amount of land assigned to field margins had a strong influence on both the number of eggs laid and the average lifespan of individuals (Fig. 4). Between the upper and lower limits of the recommended set-aside area for field margin and nectar plots by the CSS (1-3 ha per $100 \mathrm{ha}$ ), there was a 1.6x increase in the number of eggs laid in the field margin, and mean lifespan increased, from 4.5 to 5.5 days. Across the full range of values tested $(0.5-4 \mathrm{ha})$, there was over a $3 x$ difference in the number of eggs laid and an increase in $\sim 1.5$ days in average lifespan. The quality of the margin (density of flowers) had a more modest effect on outcomes and only at low densities below 1 flower per $\mathrm{m}^{2}$ were butterflies affected, though at the highest population size, increases in eggs laid and lifespan increased approximately linearly throughout increasing flower density.

Outcomes after two weeks were generally similar, whatever the initial population size where this was below 10000, though resource competition had some effect at lower flower densities (Fig. 4C, D). At the highest population size (50000 butterflies) the effects of competition were seen in all scenarios as populations had lower lifespans and laid fewer eggs (Fig. 4). 

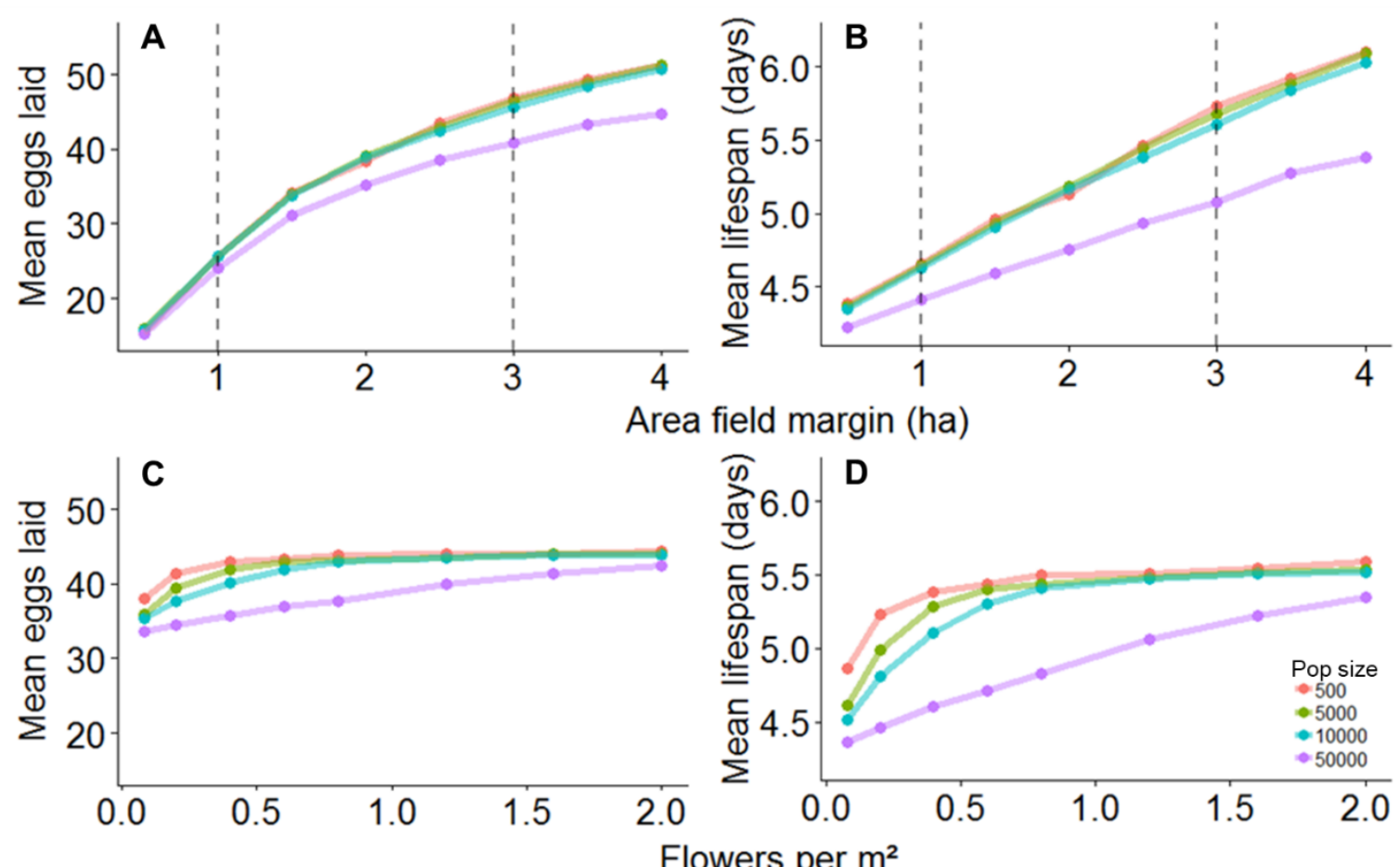

Figure 4. Responses of butterflies to the amount of quality habitat, and the density of flowers. The amount of quality habitat is measured as \% land assigned to field margins; the resultant eggs and lifespan are shown in A and B respectively. Responses to flower density are shown in $\mathrm{C}$ and D. Coloured lines show results after two weeks for different sizes of starting populations. Dashed lines in A \& B show min and max recommendations from CSS for the category "nectar-rich plots and margins".

\section{Discussion}

National declines in insect abundance and richness are generally linked to the reduction of floral resources and landscape intensification (Baude et al., 2016; Biesmeijer et al., 2006; Goulson et al., 2015; Potts et al., 2010), making the prediction of the responses of butterflies to varying habitat structures and compositions an important yet challenging task. Butterflies exhibit behaviours such as responding to habitat edges and habitat-dependent movements (Conradt et al., 2000; Conradt and Roper, 2006; Delattre et al., 2013, 2010b; Schtickzelle et al., 2007; Schultz et al., 2012) that reduce the utility of simple random walk approaches. Further, modelling the responses of life-history outcomes, such as survivorship and fecundity, requires coupling accurate movement and activity predictions with interaction with resources in the environment. The IBM model described here provided credible representations of key 
features of the behaviour and life-history responses of $M$. jurtina across different habitat types. This demonstrates the model has the potential to be a useful tool for conservation management, as it allows prediction of the effect of a particular management scenario on outcomes important for population-level effects.

We used the IBM to make some preliminary predictions of the effect of agri-environment scheme scenarios on life-history outcomes for M. jurtina. The effectiveness of these schemes is of considerable interest, with evidence accumulating towards the necessary requirement of set-aside to sustain populations (Dicks et al., 2015; Redhead et al., 2015; Sutton et al., 2017). While generally more is better (Fig. 4), egg production showed diminishing returns from increasing the proportion of land assigned to field margins. Such results are important in evaluating trade-offs between improving habitat for butterflies and maximising productive land for economic benefit.

Compared to the extent of field margins, flower density and population size had smaller effects on average fecundity and lifespan. For flower density, this suggests that flower resources are not limiting at moderate densities. It is also possible that for M. jurtina, whose larvae feed on grass, flower densities are generally less important than locating suitable habitat in which to lay eggs, as even with access to sparse and poor quality resources, butterflies are able to sustain themselves through increased lipid use over the first few days (Fig. 3) (Lebeau et al., 2016b) coinciding with periods of maximum fecundity (Berger et al., 2008; Gibbs et al., 2010a, 2010b). Consequently, with access to grassy habitats, they should remain fecund even in low resource environments. The small effect of initial population sizes below 100/ha suggests that competition is then of minor importance. It is, however, possible that competition effects not included in the model such as male territorial behaviour (Shreeve, 1984) or female harassment (Odendaal et al., 1989) may increase the effect of population densities on life-history outcomes.

The model has further limitations worth addressing. Our activity budgets and movement rates were habitat-dependent, as is found across multiple butterfly species (Brown and Crone, 2016b; Delattre et al., 2010a; Fownes and Roland, 2002; Ovaskainen et al., 2008a; J. Roland et al., 2000; Schtickzelle et al., 2007). However, the extent to which movement and activity respond dynamically to habitat quality in terms of the number of resources perceived by individuals is not well understood for any species (Bartumeus et al., 2016; Nathan et al., 2008). To build models that can handle these dynamic effects may require developing 
frameworks and theory of a higher order that attempt to understand how animals adapt movements to both their local conditions and current motivations, and so better represent behaviour in novel conditions (Nathan et al., 2008). Despite these caveats, the model was able to well match empirical patterns across a range of metrics, suggesting that it offers insight into the response of $M$. jurtina to the range of scenarios explored here.

The sensitivity analysis demonstrated that lipid reserve use, and therefore longevity was sensitive to both the quantity of sugar in the nectar and the rate of replenishment of nectar in flowers (Lebeau et al., 2016b). There is therefore potential for the model to be used to explore more broadly the relationship between nectar quality and life-history outcomes in agri-environment schemes. The CSS (Defra, 2019) recommends flower species for use in nectar plots and margins, and numerous commercial seed mixes are also available for this task, with the sugar content of many of these resources quantified (Hicks et al., 2016). This information and the IBM provide the potential to quantify in more detail the effect of specific management scenarios on $M$. jurtina. Finally, although the model here is parameterised for M. jurtina there is potential for the model to be applied to other butterfly species by scaling movement, activity and metabolism to body size and modifying host plants and nectar resources appropriately. Viewing the differences between butterfly species in terms of parameters that influence the movement, activity and response to habitat structure and composition could provide a useful conceptual framework for understanding the differences in the response of different species to changing habitats and landscapes.

\section{Conclusion}

IBMs have the potential to address management issues which are challenging to study experimentally or to model without the inclusion of the detailed processes which ultimately drive outcomes (Evans, 2012). Here we have developed a process rich model IBM to attempt to address the question of how the quantity and quality of field margins influence life-history outcomes for butterflies. We hope this builds on the large successes in butterfly movement modelling and provides a platform for further investigation of applied conservation questions, providing insight much required in a rapidly changing world. 


\section{References}

Asher, J., Warren, M., Fox, R., Harding, P., Jeffcoate, G., Jeffcoate, S., 2001. The millennium atlas of butterflies in Britain and Ireland. Oxford University Press.

Barr, C.J., Bunce, R.G.H., Parr, T.W., 1994. Countryside Survey 1990. Annu. Rep. Inst. Terr. Ecol. 1993, 20-26.

Bartumeus, F., Campos, D., Ryu, W.S., Lloret-Cabot, R., Méndez, V., Catalan, J., 2016. Foraging success under uncertainty: search tradeoffs and optimal space use. Ecol. Lett. 19, 1299-1313. https://doi.org/10.1111/ele.12660

Baude, M., Kunin, W.E., Boatman, N.D., Conyers, S., Davies, N., Gillespie, M.A.K., Morton, R.D., Smart, S.M., Memmott, J., 2016. Historical nectar assessment reveals the fall and rise of floral resources in Britain. Nature 530, 85-88. https://doi.org/10.1038/nature16532

Berger, D., Walters, R., Gotthard, K., 2008. What limits insect fecundity? Body size- and temperature-dependent egg maturation and oviposition in a butterfly. Funct. Ecol. 22, 523-529. https://doi.org/10.1111/j.1365-2435.2008.01392.x

Biesmeijer, J.C., Roberts, S.P., Reemer, M., Ohlemüller, R., Edwards, M., Peeters, T., Schaffers, A.P., Potts, S.G., Kleukers, R., Thomas, C.D., Settele, J., 2006. Parallel Declines in Pollinators and Insect-Pollinated Plants in Britain and the Netherlands. Science (80-. ). 313, 351-354. https://doi.org/10.1126/science.1127863

Brakefield, P.M., 1982a. Ecological Studies on the Butterfly Maniola jurtina in Britain. I. Adult Behaviour, Microdistribution and Dispersal. J. Anim. Ecol. 51, 713. https://doi.org/10.2307/4000

Brakefield, P.M., 1982b. Ecological Studies on the Butterfly Maniola jurtina in Britain. II. Population Dynamics: The Present Position. J. Anim. Ecol. 51, 727. https://doi.org/10.2307/4001

Brown, L.M., Crone, E.E., 2016a. Individual variation changes dispersal distance and area requirements of a checkerspot butterfly. Ecology 97, 106-115. https://doi.org/10.1002/ecy.1216

Brown, L.M., Crone, E.E., 2016b. Minimum area requirements for an at-risk butterfly based on movement and demography. Conserv. Biol. 30, 103-112. https://doi.org/10.1111/cobi.12588

Chamberlain, D.E., Fuller, R.J., Bunce, R.G.H., Duckworth, J.C., Shrubb, M., 2000. Changes in the abundance of farmland birds in relation to the timing of agricultural intensification in England and Wales. J. Appl. Ecol. 37, 771-788. https://doi.org/10.1046/j.1365-2664.2000.00548.x

Clements, A.N., 1992. The biology of mosquitoes. Volume 1: development, nutrition and reproduction. Chapman \& Hall.

Conradt, L., Bodsworth, E.J., Roper, T.J., Thomas, C.D., 2000. Non-random dispersal in the butterfly Maniola jurtina: implications for metapopulation models. Proc. R. Soc. B Biol. Sci. 267, 15051510. https://doi.org/10.1098/rspb.2000.1171

Conradt, L., Roper, T.J., 2006. Nonrandom movement behavior at habitat boundaries in two butterfly species: Implications for dispersal. Ecology 87, 125-132. https://doi.org/10.1890/05-0413

Curtis, R.J., Brereton, T.M., Dennis, R.L.H., Carbone, C., Isaac, N.J.B., 2015. Butterfly abundance is determined by food availability and is mediated by species traits. J. Appl. Ecol. 52, 1676-1684. https://doi.org/10.1111/1365-2664.12523

Defra, 2019. Countryside Stewardship: Mid Tier and Wildlife Offers Manual.

Delattre, T., Burel, F., Humeau, A., Stevens, V.M., Vernon, P., Baguette, M., 2010a. Dispersal mood revealed by shifts from routine to direct flights in the meadow brown butterfly Maniola jurtina. Oikos 119, 1900-1908. https://doi.org/10.1111/j.1600-0706.2010.18615.x 
Delattre, T., Pichancourt, J.-B., Burel, F., Kindlmann, P., 2010b. Grassy field margins as potential corridors for butterflies in agricultural landscapes: A simulation study. Ecol. Modell. 221, 370377. https://doi.org/10.1016/j.ecolmodel.2009.10.010

Delattre, T., Vernon, P., Burel, F., 2013. An agri-environmental scheme enhances butterfly dispersal in European agricultural landscapes. Agric. Ecosyst. Environ. 166, 102-109. https://doi.org/10.1016/j.agee.2011.06.018

Dennis, R.L.H., 1992. Ecology of butterflies in Britain. Oxford University Press.

Dicks, L. V., Baude, M., Roberts, S.P.M., Phillips, J., Green, M., Carvell, C., 2015. How much flower-rich habitat is enough for wild pollinators? Answering a key policy question with incomplete knowledge. Ecol. Entomol. 40, 22-35. https://doi.org/10.1111/een.12226

Donald, P.F., Sanderson, F.J., Burfield, I.J., van Bommel, F.P.J., 2006. Further evidence of continentwide impacts of agricultural intensification on European farmland birds, 1990-2000. Agric. Ecosyst. Environ. 116, 189-196. https://doi.org/10.1016/j.agee.2006.02.007

Dover, J.W., 2019. The Ecology of Hedgerows and Field Margins. Routledge.

Duraiappah, A.K., Naeem, S., Agardy, T., Ash, N.J.., Cooper, H.D., Diaz, S., Faith, D.P.., Mace, G., McNeely, J.A.., Mooney, H.A.., Oteng-Yeboah, A.A.., Pereira, H.M., Polasky, S., Prip, A., 2005. Ecosystems and human well-being: biodiversity synthesis; a report of the Millennium Ecosystem Assessment. World Resour. Institute.

Ekroos, J., Heliölä, J., Kuussaari, M., 2010. Homogenization of lepidopteran communities in intensively cultivated agricultural landscapes. J. Appl. Ecol. 47, 459-467. https://doi.org/10.1111/j.1365-2664.2009.01767.x

Erhardt, A., Thomas, J.A., 1989. Lepidoptera as indicators of change in semi-natural grasslands. Conserv. insects their habitats.(NM Collins y JA Thomas. Eds.). Press. London 113-235.

Evans, M.R., 2012. Modelling ecological systems in a changing world. Philos. Trans. R. Soc. B Biol. Sci. 367, 181-190. https://doi.org/10.1098/rstb.2011.0172

Fownes, S., Roland, J., 2002. Effects of meadow suitability on female behaviour in the alpine butterfly Parnassius smintheus. Ecol. Entomol. 27, 457-466. https://doi.org/10.1046/j.13652311.2002.00426.x

Fox, R., Brereton, T.M., Asher, J., August, T.A., Botham, M.S., Bourn, N.A.D., Cruickshanks, K.L., Bulman, C.R., Ellis, S., Harrower, C.A., 2015. The State of the UK's Butterflies 2015.

García-Barros, E., 2006. Within and between species scaling in the weight, water, carbon and nitrogen contents of eggs and neonate larvae of twelve satyrine butterflies (Lepidoptera: Nymphalidae). Eur. J. Entomol. 103, 559-568.

Geister, T.L., Lorenz, M.W., Hoffmann, K.H., Fischer, K., 2008. Adult nutrition and butterfly fitness: Effects of diet quality on reproductive output, egg composition, and egg hatching success. Front. Zool. 5, 1-13. https://doi.org/10.1186/1742-9994-5-10

Gibbs, M., Breuker, C.J., Hesketh, H., Hails, R.S., Van Dyck, H., 2010a. Maternal effects, flight versus fecundity trade-offs, and offspring immune defence in the Speckled Wood butterfly, Pararge aegeria. BMC Evol. Biol. 10. https://doi.org/10.1186/1471-2148-10-345

Gibbs, M., Breuker, C.J., Van Dyck, H., 2010b. Flight during oviposition reduces maternal egg provisioning and influences offspring development in Pararge aegeria (L.). Physiol. Entomol. 35, 29-39. https://doi.org/10.1111/j.1365-3032.2009.00706.x

Goulson, D., Nicholls, E., Botias, C., Rotheray, E.L., 2015. Bee declines driven by combined stress from parasites, pesticides, and lack of flowers. Science (80-. ). 347, 1255957-1255957. https://doi.org/10.1126/science.1255957 
Grant, T.J., Parry, H.R., Zalucki, M.P., Bradbury, S.P., 2018. Predicting monarch butterfly (Danaus plexippus) movement and egg-laying with a spatially-explicit agent-based model: The role of monarch perceptual range and spatial memory. Ecol. Modell. 374, 37-50.

Grill, A., Cerny, A., Fiedler, K., 2013. Hot summers, long life: Egg laying strategies of Maniola butterflies are affected by geographic provenance rather than adult diet. Contrib. to Zool. 82, 2736.

Grimm, V., 2005. Pattern-Oriented Modeling of Agent-Based Complex Systems: Lessons from Ecology. Science (80-. ). 310, 987-991. https://doi.org/10.1126/science.1116681

Grimm, V., Berger, U., Bastiansen, F., Eliassen, S., Ginot, V., Giske, J., Goss-Custard, J., Grand, T., Heinz, S.K., Huse, G., 2006. A standard protocol for describing individual-based and agentbased models. Ecol. Modell. 198, 115-126.

Grimm, V., Berger, U., DeAngelis, D.L., Polhill, J.G., Giske, J., Railsback, S.F., 2010. The ODD protocol: A review and first update. Ecol. Modell. 221, 2760-2768. https://doi.org/10.1016/j.ecolmodel.2010.08.019

Hainsworth, F.R., Precup, E., Hamill, T., 1991. Feeding, energy processing rates and egg production in painted lady butterflies. J. Exp. Biol. 156, 249-265.

Hicks, D.M., Ouvrard, P., Baldock, K.C.R., Baude, M., Goddard, M.A., Kunin, W.E., Mitschunas, N., Memmott, J., Morse, H., Nikolitsi, M., Osgathorpe, L.M., Potts, S.G., Robertson, K.M., Scott, A. V., Sinclair, F., Westbury, D.B., Stone, G.N., 2016. Food for Pollinators: Quantifying the Nectar and Pollen Resources of Urban Flower Meadows. PLoS One 11, e0158117. https://doi.org/10.1371/journal.pone.0158117

Hill, R.W., Wyse, G.A., Anderson, M., Anderson, M., 2004. Animal physiology. Sinauer Associates ^ eMassachusetts Massachusetts.

Kleiber, M., 1961. The fire of life. An introduction to animal energetics. fire life. An Introd. to Anim. Energ.

Lebeau, J., 2015. Nectar resource limitation in agricultural landscapes : effects on behaviour and lifehistory traits in the meadow brown butterfly (Maniola jurtina). PhD Thesis.

Lebeau, J., Wesselingh, R.A., Van Dyck, H., 2016a. Nectar resource limitation affects butterfly flight performance and metabolism differently in intensive and extensive agricultural landscapes. Proc. R. Soc. B Biol. Sci. 283, 20160455. https://doi.org/10.1098/rspb.2016.0455

Lebeau, J., Wesselingh, R.A., Van Dyck, H., 2016b. Floral resource limitation severely reduces butterfly survival, condition and flight activity in simplified agricultural landscapes. Oecologia 180, 421-427. https://doi.org/10.1007/s00442-015-3492-2

Lund, U., Agostinelli, C., 2011. R package 'circular’: Circular Statistics. URL https//r-forge. r-project. org/projects/circular.

Luo, E.Y., Ogilvie, J.E., Thomson, J.D., 2014. Stimulation of Flower Nectar Replenishment By Removal: a Survey of Eleven Animal-Pollinated Plant Species. J. Pollinat. Ecol. 12, 52-62.

Luppi, M., Dondina, O., Orioli, V., Bani, L., 2018. Local and landscape drivers of butterfly richness and abundance in a human-dominated area. Agric. Ecosyst. Environ. 254, 138-148. https://doi.org/10.1016/j.agee.2017.11.020

Lutz, W., Butz, W.P., Samir, K.C. ed, 2017. World population \& human capital in the twenty-first century: an overview. Oxford University Press.

Mazer, C.L., Appel, A.G., 2001. Water Loss and Desiccation Tolerances of Longwing Butterflies(Lepidoptera: Nymphalidae). Environ. Entomol. 30, 631-636.

https://doi.org/10.1603/0046-225X-30.4.631 
McIntire, E.J.B., Rompré, G., Severns, P.M., 2013. Biased correlated random walk and foray loop: which movement hypothesis drives a butterfly metapopulation? Oecologia 172, 293-305. https://doi.org/10.1007/s00442-012-2475-9

Nathan, R., Getz, W.M., Revilla, E., Holyoak, M., Kadmon, R., Saltz, D., Smouse, P.E., 2008. A movement ecology paradigm for unifying organismal movement research. Proc. Natl. Acad. Sci. 105, 19052-19059. https://doi.org/10.1073/pnas.0800375105

Odendaal, F.J., Turchin, P., Stermitz, F.R., Odendaal, F.J., Turchin, P., Stermitz, F.R., 1989. Influence of Host-Plant Density and Male Harassment on the Distribution of Female Euphydryas anicia (Nymphalidae ) 78, 283-288.

Ovaskainen, O., Hanski, I., 2004. From Individual Behavior to Metapopulation Dynamics: Unifying the Patchy Population and Classic Metapopulation Models. Am. Nat. 164, 364-377. https://doi.org/10.1086/423151

Ovaskainen, O., Luoto, M., Ikonen, I., Rekola, H., Meyke, E., Kuussaari, M., 2008a. An Empirical Test of a Diffusion Model: Predicting Clouded Apollo Movements in a Novel Environment. Am. Nat. 171, 610-619. https://doi.org/10.1086/587070

Ovaskainen, O., Rekola, H., Meyke, E., Arjas, E., 2008b. Bayesian methods for analyzing movements in heterogeneous landscapes from mark-recapture data. Ecology 89, 542-554. https://doi.org/10.1890/07-0443.1

Petit, S., Howard, D.C., Smart, S.M., Firbank, L.G., 2002. Biodiversity in British agro-ecosystems: the changing regional landscape context, in: Brighton Crop Protection Conference Pests and Diseases. pp. 957-964.

Pollard, E., Yates, T.J., 1994. Monitoring butterflies for ecology and conservation: the British butterfly monitoring scheme. Springer Science \& Business Media.

Potts, S.G., Biesmeijer, J.C., Kremen, C., Neumann, P., Schweiger, O., Kunin, W.E., 2010. Global pollinator declines: trends, impacts and drivers. Trends Ecol. Evol. 25, 345-353. https://doi.org/10.1016/j.tree.2010.01.007

Potts, S.G., Imperatriz-Fonseca, V., Ngo, H.T., Aizen, M.A., Biesmeijer, J.C., Breeze, T.D., Dicks, L. V., Garibaldi, L.A., Hill, R., Settele, J., Vanbergen, A.J., 2016. Safeguarding pollinators and their values to human well-being. Nature 540, 220-229. https://doi.org/10.1038/nature20588

Pywell, R.F., Warman, E.A., Sparks, T.H., Greatorex-Davies, J.N., Walker, K.J., Meek, W.R., Carvell, C., Petit, S., Firbank, L.G., 2004. Assessing habitat quality for butterflies on intensively managed arable farmland. Biol. Conserv. 118, 313-325. https://doi.org/10.1016/j.biocon.2003.09.011

Redhead, J.W., Dreier, S., Bourke, A.F.G., Heard, M.S., Jordan, W.C., Sumner, S., Wang, J., Carvell, C., 2015. Effects of habitat composition and landscape structure on worker foraging distances of five bumblebee species. Ecol. Appl. 26, 150819033522003. https://doi.org/10.1890/15-0546.1

Robinson, R.A., Sutherland, W.J., 2002. Post-war changes in arable farming and biodiversity in Great Britain. J. Appl. Ecol. 39, 157-176. https://doi.org/10.1046/j.1365-2664.2002.00695.x

Roland, Jens, Keyghobadi, N., Fownes, S., 2000. Alpine Parnassius butterfly dispersal: effects of landscape and population size. Ecology 81, 1642-1653.

Roland, J., Keyghobadi, N., Fownes, S., 2000. Alpine Parnassius butterfly dispersal: Effects of landscape and population size. Ecology 81, 1642-1653. https://doi.org/10.1890/00129658(2000)081[1642:APBDEO]2.0.CO;2

Sánchez-Bayo, F., Wyckhuys, K.A.G., 2019. Worldwide decline of the entomofauna: A review of its drivers. Biol. Conserv. 232, 8-27. https://doi.org/10.1016/j.biocon.2019.01.020 
Scali, V., 1971. Imaginal Diapause and Gonadal Maturation of Maniola jurtina (Lepidoptera: Satyridae) from Tuscany. J. Anim. Ecol. 40, 467. https://doi.org/10.2307/3255

Schtickzelle, N., Joiris, A., Dyck, H. Van, Baguette, M., 2007. Quantitative analysis of changes in movement behaviour within and outside habitat in a specialist butterfly. BMC Evol. Biol. 7, 115. https://doi.org/10.1186/1471-2148-7-4

Schultz, C.B., Crone, E.E., 2001. Edge-Mediated Dispersal Behavior in a Prairie Butterfly. Ecology 82, 1879. https://doi.org/10.2307/2680054

Schultz, C.B., Franco, A.M.A., Crone, E.E., 2012. Response of butterflies to structural and resource boundaries. J. Anim. Ecol. 81, 724-734. https://doi.org/10.1111/j.1365-2656.2011.01947.x

Scriber, J.M., Maher, E., Aardema, M.L., 2012. Differential effects of short term winter thermal stress on diapausing tiger swallowtail butterflies (Papiliospp.). Insect Sci. 19, 277-285. https://doi.org/10.1111/j.1744-7917.2011.01477.x

Shreeve, T.G., 1995. Butterfly mobility, in: Ecology and Conservation of Butterflies. Springer Netherlands, Dordrecht, pp. 37-45. https://doi.org/10.1007/978-94-011-1282-6_3

Shreeve, T.G., 1984. Habitat selection, mate location, and microclimatic constraints on the activity of the speckled wood butterfly Pararge aegeria. Oikos 42, 371-377.

https://doi.org/10.2307/3544407

Sibly, R.M., Grimm, V., Martin, B.T., Johnston, A.S. a., Kułakowska, K., Topping, C.J., Calow, P., Nabe-Nielsen, J., Thorbek, P., DeAngelis, D.L., 2013. Representing the acquisition and use of energy by individuals in agent-based models of animal populations. Methods Ecol. Evol. 4, 151161. https://doi.org/10.1111/2041-210x.12002

Sutton, B.P.B., Coates, G., Bailey, B., Nowakowski, M., Edwards, M., 2017. Operation Pollinator: Positive action for pollinators and improved biodiversity in arable landscapes 121-130.

Team, R.C., 2018. R: A language and environment for statistical computing. R Foundation for Statistical Computing, Vienna, Austria. 2017.

Thiele, J.C., 2014. R Marries NetLogo : Introduction to the RNetLogo Package. J. Stat. Softw. 58, 141. https://doi.org/10.18637/jss.v058.i02

Thiele, J.C., Kurth, W., Grimm, V., 2014. Facilitating parameter estimation and sensitivity analysis of agent-based models: A cookbook using NetLogo and R. J. Artif. Soc. Soc. Simul. 17, 11.

Thomas, J.., 2005. Monitoring change in the abundance and distribution of insects using butterflies and other indicator groups. Philos. Trans. R. Soc. B Biol. Sci. 360, 339-357. https://doi.org/10.1098/rstb.2004.1585

van der Vaart, E., Beaumont, M. a., Johnston, A.S. a., Sibly, R.M., 2015. Calibration and evaluation of individual-based models using Approximate Bayesian Computation. Ecol. Modell. 312, 182190. https://doi.org/10.1016/j.ecolmodel.2015.05.020

Vanbergen, A.J., Garratt, M. P., Vanbergen, A.J., Baude, M., Biesmeijer, J.C., Britton, N.F., Brown, M.J.F., Brown, M., Bryden, J., Budge, G.E., Bull, J.C., Carvell, C., Challinor, A.J., Connolly, C.N., Evans, D.J., Feil, E.J., Garratt, Mike P., Greco, M.K., Heard, M.S., Jansen, V.A.A., Keeling, M.J., Kunin, W.E., Marris, G.C., Memmott, J., Murray, J.T., Nicolson, S.W., Osborne, J.L., Paxton, R.J., Pirk, C.W.W., Polce, C., Potts, S.G., Priest, N.K., Raine, N.E., Roberts, S., Ryabov, E. V., Shafir, S., Shirley, M.D.F., Simpson, S.J., Stevenson, P.C., Stone, G.N., Termansen, M., Wright, G.A., 2013. Threats to an ecosystem service: Pressures on pollinators. Front. Ecol. Environ. 11, 251-259. https://doi.org/10.1890/120126

Vande Velde, L., Van Dyck, H., 2013. Lipid economy, flight activity and reproductive behaviour in the speckled wood butterfly: On the energetic cost of territory holding. Oikos 122, 555-562. 
https://doi.org/10.1111/j.1600-0706.2012.20747.x

Vickery, J.A., Feber, R.E., Fuller, R.J., 2009. Arable field margins managed for biodiversity conservation: A review of food resource provision for farmland birds. Agric. Ecosyst. Environ. 133, 1-13. https://doi.org/10.1016/j.agee.2009.05.012

Wagner, D., del Rio, C.M., 1997. Experimental tests of the mechanism for ant-enhanced growth in an ant-tended lycaenid butterfly. Oecologia 112, 424-429. https://doi.org/10.1007/s004420050328

Watt, W.B., Hoch, P.C., Mills, S.G., 1974. Nectar resource use by Colias butterflies - Chemical and visual aspects. Oecologia 14, 353-374. https://doi.org/10.1007/BF00384578

Wiklund, C., Karlsson, B., 2019. Nordic Society Oikos Egg Size Variation in Satyrid Butterflies : Adaptive vs Historical , " Bauplan ", and Mechanistic Explanations Author ( s ): Christer Wiklund and Bengt Karlsson Published by: Wiley on behalf of Nordic Society Oikos Stable URL : https 43, 391-400.

Wilensky, U., 1999. NetLogo. Evanston, IL: Center for connected learning and computer-based modeling, Northwestern University.

Zalucki, M.P., Kitching, R.L., 1982. The Analysis and Description of Movement in Adult Danaus Plexippus L. (Lepidoptera: Danainae). Behaviour 80, 174-197.

https://doi.org/10.1163/156853982X00346 